\title{
Reverse Logistics: RFID the key to optimality
}

\author{
Rezwan Asif \\ Linköping University (SWEDEN) \\ rezwanasif06@yaboo.com
}

Received January 2011

Accepted May 2011

\section{Abstract:}

Purpose: The purpose of this paper is to find ways to reduce uncertainties in Reverse logistic supply chain (RLSC) through the use of Radio-frequency identification (RFID) technology.

Design/methodology/approach: This paper reviews literature and builds model to relate RFID with uncertainties in order to optimize Reverse Logistics.

Findings: RFID is really efficient to determine and detect quantity, variety and cycle times of returns; however it's not as convenient to determine quality of the returns. The collected information from RFID can be used to standardize the RLSC.

Research limitations: Though it's several and unique advantages some limitations of RFID have been identified in quality and processing sequence, collecting points and different standards, and in global usage.

Originality/value: Previous studies in the area of Reverse Logistics and RFID don't cover all impacts of this technology on RLSC. This review paper has investigated these impacts and offers a model for optimizing the Reverse Logistics Supply Chain.

Keywords: reverse logistics, RFID, uncertainties, closed-loop supply chain 


\section{Introduction}

According to Visich, $\mathrm{Li}$ and Khumawala (2007), "When customers return their purchases to retailers for refund, repair or a recall, an upstream movement of goods occurs from the retailer to manufacturer. This upstream movement of product returns is termed as reverse supply chain". Reuse of products and materials become essential from two aspects. On the one hand, economical issues of reusing encourage manufacturers to find ways to ensure the return of their manufactured products after a period of time and give them the advantage to reuse and make more profit. On the other hand, nowadays environmental issues become a critical concern for any decision. Therefore manufacturers have to find some ways to be more "Green"; otherwise they may lose those customers concerned about environment, besides governments give more support to the Green manufacturers.

But since Reverse Logistics ( $R L$ ) are more complex compare to forward logistics (Poole, 2003), the information management becomes the key to create an efficient supply chain (Jayaraman, Ross, \& Agarwal, 2008). Research by Guide, Harrison and Van Wassenhove (2003) states that "Managers must take actions to reduce uncertainty in the timing and quantity of returns, balance return rates with demand rates, and make material recovery more predictable. Managers must also plan for the collection of products from end users. The use of information systems with new production-planning and control techniques makes management of those activities more predictable."

Most of the papers investigating RL have mentioned this complexity resulting from uncertainties and suggested solutions from the point of IT. But in this paper the characteristics of RFID are considered specifically in order to reduce uncertainties and a model is suggested to show the impact of the advantages of RFID on RLSC.

\section{Background}

\subsection{Radio-frequency identification (RFID)}

RFID is the use of an object called RFID tag which is applied to a product, animal, or person for the purpose of identification and tracking by using radio waves. RFID tags support a larger set of unique data than bar codes and can incorporate 
additional data such as manufacturer, product type, and even measure environmental factors such as temperature (Want, 2006). Its mainstream applications help speed the handling of manufactured goods and materials by enabling identification and tracking from a distance and without the line of sight.

According to Want (2006), many types of RFID exist globally but at the highest level, RFID devices can be divided into two classes: active and passive. Active tags require a power source, either connected to a powered infrastructure or use energy stored in an integrated battery. One example of active tag is transponder attached to an aircraft that identifies its national origin. Passive RFID tags do not require batteries or maintenance and have an indefinite operational life. In contrast to active RFID tags, passive tags are usually smaller and less expensive. For example in transportation and logistics where yard management, shipping and distribution are advanced by using RFID tracking

\section{Advantages of RFID over bar codes}

Ever since the advent of large-scale manufacturing, rapid identification and tracking techniques have helped speed the handling of goods and materials and increase the efficiency of supply chain. In the 1970s, labeling made a giant leap forward with the introduction of Universal Product Code (type of bar code) which helped to automate and standardize the identification process.

\begin{tabular}{|c|c|c|}
\hline Characteristics & Bar Code & RFID \\
\hline 1. Automation & $\begin{array}{l}\text { Not fully automated. Requires } \\
\text { manual labour and more time. }\end{array}$ & $\begin{array}{l}\text { Fully automated. Requires } \\
\text { less manual labour and time. }\end{array}$ \\
\hline 2. Bulk Reading & Not possible. & Possible. \\
\hline $\begin{array}{l}\text { 3. Line of sight between reader } \\
\text { and tag }\end{array}$ & Mandatory. & Not mandatory. \\
\hline 4. Visibility & $\begin{array}{l}\text { Mandatory. High chances to be } \\
\text { obscured by grease, tape, } \\
\text { sunlight and nearby objects. }\end{array}$ & Not mandatory. \\
\hline 5. Tracking & Not possible. & Possible in every step. \\
\hline 6. Content and container & $\begin{array}{l}\text { Identify the containers only not } \\
\text { the contents inside the } \\
\text { containers. }\end{array}$ & $\begin{array}{l}\text { Possible to identify the } \\
\text { contents inside the containers } \\
\text { themselves. }\end{array}$ \\
\hline
\end{tabular}

Table 1. "Advantage of RFID over bar code". Source: Thoroe, Melski and Schumann (2009) and Want (2006) 
Bar codes are also cheap to produce, but they have many limitations. According to Thoroe, Melski and Schumann (2009) and Want (2006), there are some certain advantages of RFID over bar code which is shown in table 1.

Besides reducing the number of operators' mistakes in the shipment process, RFID technology can improve the economy of scale. Indeed, thanks to the remote readers all along the supply chain, there is no need for employees to read directly the tags whereas the barcode technology needs more human resources.

\section{RFID in Reverse Logistics}

RL generally give efforts on activities surrounding the return and processing of returned products. They are at first usually collected at the point of sale and also in collection points, then inspected and sorted by employees to the best of their knowledge. Moreover, the employee determines if the return is accepted and the actions to be taken later on. Thereafter, a certain amount of time can pass before further actions are taken in regards to those recovered products (Chouinard, D'Amours, \& Ait-Kadi, 2005). Due to its unique advantages such as bulk reading, fully automation and no line of sight, the required time, labour and cost for collection and sorting are reduced. To increase the value of the returned products, decisions are made whether to repair, refurbish, remanufacture, cannibalize or recycle the products (Visich, Li, \& Khumawala, 2007). The tracking and identification characteristics of the RFID give information about the quality of the returned products, advantages on making the right decisions and also reduce thievery. So RFID-based solutions have proven to help businesses reduce costs, fine-tune inventory management, fortify theft detection, and achieve new velocity with real-time visibility into business processes across the whole RLSC.

\section{$\underline{\text { RFID standards }}$}

There are many well-established standards and a few emerging standards of RFID. Standards are critical for many RFID applications, such as payment systems and tracking goods or reusable containers because of the variation from environment to environment. Some examples of RFID standards are given in table 2. 


\begin{tabular}{|l|l|}
\hline \multicolumn{1}{|c|}{ ISO Number } & \multicolumn{1}{c|}{ Title } \\
\hline ISO 11784 & Radio frequency identification of animals (Code structure) \\
\hline ISO 11785 & Radio frequency identification of animals (Technical concept) \\
\hline ISO 14223 & $\begin{array}{l}\text { Specifies the air interface between the transceiver and the advanced transponder } \\
\text { used in the radio frequency identification of animals under the condition of full } \\
\text { upward compatibility according to ISO 11784 and ISO 11785. }\end{array}$ \\
\hline ISO/IEC 24752 & $\begin{array}{l}\text { Information technology -Automatic Identification and Data Capture Techniques- } \\
\text { Radio Frequency Identification (RFID) for Item Management -System Management } \\
\text { Protocol }\end{array}$ \\
\hline
\end{tabular}

Table 2. "Examples of RFID standards". Source: The RFID Network (http://rfid.net/) and the RFID Journal (http://www.rfidjournal.com/)

\subsection{Uncertainties: forward vs. reverse logistics}

Reuses have different forms. According to Thierry, Salomon, Van Nunen and Van Wassenhove (1995), these are categorized in four main group: direct reuse, recycling, repair and remanufacturing. The most important characteristic of RL, which distinct it from Forward Logistic (FL) is the non-standard process which is the result of uncertainties in RL (Visich, Li, \& Khumawala, 2007). The uncertainty issue in $\mathrm{RL}$ has been mentioned by most authors in $\mathrm{RL}$ related literatures. For example in the research paper by Fleischmann and Bloemhof Ruwaard (1997), the word "uncertainty" has been used in the text for 19 times. They explain in this paper that the uncertainties are in all activities in the RLSC, such as transportations, distribution planning, inventory control, production planning, etc.

Different papers in the area of $\mathrm{RL}$ mentioned different uncertainties. For example research by Visich, Li and Khumawala (2007), has more focus on quality while Lee and Chan (2008), has more focus on quantity. Therefore after reading related articles these uncertainties have been sorted into five main groups: quantity, variety, cycle time, quality, and market trends.

Some people argue that the impact of RFID in both FL and RL is the same. However, in the $\mathrm{FL}$, manufacturers have most information that they need to plan the supply chain. For example, inventory, lead times and they have usually a good estimation on the market demand. Besides, nowadays Pull system is becoming more popular over the traditional Push system and some companies shifted to Pull from Push system. However, the returns system are push, this means that customers push the returns to manufacturers. Then the manufacturers (at 
collection points) have no choice but to accept them and if they do not have an efficient production (remanufacturing, cannibalization, etc.) planning they have to dispose them because of inventory costs.

A short comparison between these five parameters in both $F L$ and $R L$ is presented below to enlighten how these parameters become important in RL.

Quantity

In FL, the volume of the finished products in the supply chain can be easily calculated by knowing the amount of products in inventories and products that are transporting. If Pull system is used, it is even much easier to have the amount of finished products in supply chain by using Kanban system. In contrary, RL is the flow from downstream to up stream. In this flow, the collection of different amount of returned products in collecting points or at the selling points is done. Generally, they are in low quantities and high variety. In order to sort these products they usually transport them in bulk to Central Collecting Points (CCP). It may take weeks or months having the returns in CCP (from the time customers delivered them to collecting points). So up to this point, the amount of returns is not identified. Even when operators sort the returns into categories at $\mathrm{CCP}$, they might make some mistakes since they are human and also the variety of the returns is very high.

\section{Variety}

Concerning the FL, different products are packed at the end of assembly lines (finished products) and there are very few difficulties with sorting process. Actually in most production lines, only one product is manufactured at a time so there is no problem to sort the finished products. However, on the other side in RL, products have to be identified and sorted at CCP. Since the variety of returns is very high, experienced operators are needed to sort them.

Quality

The qualities of forwarded and returned products differ magnificently. Indeed, one of the main reasons customers return products is that the quality levels of the products decrease after a while. Moreover they occasionally return their own products to be repaired or reshaped to get a higher quality. 


\section{Cycle time}

The lead time (production time) for products is known in FL and its deviation is very low while the cycle times highly differ from customer to customer in RL. Even for a unique customer it is different from time to time. Therefore identifying and detecting the average of returns in different periods of time is very important. These averages and standard deviations could be used further for forecasting which would help in future product developments.

\section{Market trends}

The levels of uncertainty in market trends are almost same in both FL and RL. But by identifying and detecting market trends earlier, a better forecast can be achieved. This leads to reduction in other four types of uncertainties mentioned before.

\section{Literature review}

A general idea about the RLSC is given by Pool (2003), who investigates the importance of IT in service part supply chains, and offers a transformation blue print to achieve the world-class status in service parts. Research by Fleischmann and Bloemhof-Ruwaard (1997), gives a good background about RL by exploring it in three subcategories: reverse distribution, inventory control and recovery planning. For each of these fields the paper has discussed implication of the emerging reuse effort, reviewed the mathematical models and identified the future research opportunities. Considering the economical aspect of RL; Chouinard, D'Amours and Aït-Kadi (2005) shows that a better control over cost in addition to the economic and environmental gain is possible if $\mathrm{RL}$ activities can be integrated and coordinated within an organization's supply chain. Moreover Jayaraman, Ross and Agarwal (2008), analyses the importance of IT and its collaboration in the reverse flows of the Closed-Loop Supply Chain (CLSC). It presents an analytical model to highlight the factors impacting the costs of the channel bottleneck and a mathematical model to evaluate the different costs. A study of two large companies in the electronic industry is done to show the importance of the use of RFID technology to reduce those costs. Visich, Li and Khumawala (2007), consider RFID usage in CLSC and show how it can improve the value of returned products through detection and identification. 
Research by Want (2006) deals with the history, development, types, importance, challenges and application of RFID. According to the writer, RFID's potential benefits are large. Many novel applications are sure to be seen in the near future, some of which we cannot even begin to imagine. Lee and Chan (2008) go further by introducing RFID-based RL systems and apply a genetic algorithm as well to optimize the coverage of the returned products for collection points. Research by Trappey, Trappey and Wu (2010) aims to model and evaluate the performance of RFID technology by a qualitative and quantitative approach. Fuzzy Cognitive Maps (mathematical model) are built to help operation managers to predict and improve the RL process. The authors use a cold storage container management case to show how the model helps to find out the potential improvements of the supply chain using RFID in RL. In a literature survey Sarac, Nabil and Dauzère-Péres (2010) covers the potential benefit of RFID technologies in supply chain by focusing on cost reduction and value creation, inventory inaccuracy, the bullwhip effect and replenishment policies. Their survey provides several advantages of RFID technology which include improvement of traceability, visibility and information accuracy; increase in efficiency and speed of processes; reduction in inventory losses; and facilitation of management through real-time information.

Some other cases studies have been reviewed as well. Indeed, in a research by Kumar, Dieveney and Dieveney (2009), the RL within the pharmaceutical industry supply chain is studied. The authors particularly found that the RFID tracking capability is beneficial for both $\mathrm{FL}$ and $\mathrm{RL}$, helping specifically to the reduction of counterfeit drugs entering the supply chain. Besides, the authors pointed out the multiple benefits of adopting standard RFID system for the industry. The second case study by Langer, Forman, Kekre and Scheller-Wolf (2007), brings out the multiple alternatives for using RFID in a particular company. In this case, RFID is used not just as an advanced barcode, but as a technology to leverage warehouse operation accuracy, consumer perception and fill rates, to reduce stock outs, to increase the efficiency of the outbound dock operations and to eliminate incorrect loadings and shipment errors. Üstündag, Baysan and Çevikcan (2007), study the importance of RFID tags quality on RL cost thanks to a simulation based on a fake company they invented. The case study shows that high quality and reusable tags with high price are more interesting to reduce the total cost. This study is only based on three factors: the batch size, the tag price and the quality of the tags. Kärkkäinen (2003) studies the benefits of RFID as a tool to increase the efficiency 
in supply chain for short shelf life products. The study shows that the business revenue increases and the greatest payback potential can be achieved for recyclable transport units. Finally Thoroe, Melski and Schumann (2009) study and analyze the impact of RFID on container management from a theoretical perspective and find out that the container return rates increases and management cost of returnable containers decreases.

\section{Results and analysis}

\subsection{RFI D impact on RLSC uncertainties}

The comparison made earlier shows that in FL the main issue is multi-echelon inventory and the bullwhip effect that can be diminished by sharing information with different parties along the supply chain. The main challenge in $R L$ is uncertainties in quantity, variety, quality, cycle time and market trend. The source of these uncertainties is the absence of an appropriate planning that has made it difficult to standardize activities within the RL (Fleischmann \& Bloemhof-Ruwaard, 1997). In order to schedule and control activities, accurate information is essential. For example in Master Production Scheduling (MPS); lead time (cycle time), forecasting volume (market trends), demand and available to promise (the available returns, quantity and variety, within the RLSC) are the information needed to complete the MPS table. The more precise information can be found the better control over the RLSC can be gained. This information can be collected by implementing RFID in the RLSC. After their literature survey Sarac, Nabil and Dauzère-Péres (2010) have observed that the main areas that RFID can deal with are inventory inaccuracy, the bullwhip effect and replenishment policies. By using RFID, inventory inaccuracy and replenishment policies can be optimized, which is very efficient in reducing RLSC uncertainties, especially in quantity, quality and variety. How RFID can collect these data and the reasons why these data are important are explained in more details below.

\section{Quantity}

According to Jayaraman, Ross and Agarwal (2008), the uncertainties in RLSC come from the lack of information in the remanufacturing process. Some information is missing in the timing and the quantity of return, in the disassembly process and in the material recovery. 
RFID technology gives the possibility to detect the quantity of products in each batch. According to Lee and Chan (2008), by detecting the quantity, the efficiency could be improved in three main areas: first, the cost of transportation could be reduced by indentifying the available inventory of each different party of the RLSC. Then, the more accurate production planning can be done by knowing the available returns for each type of products (e.g. the amount of products for cannibalization is known). And finally, best locations can be chosen for collection points.

\section{$\underline{\text { Inventory control and planning }}$}

RFID technology can improve the inventory control of returned products and allows the planner to further optimize the inventory planning, particularly if the company uses Material Requirements Planning (MRP).

The aim of supply chain managers in $\mathrm{RL}$ is to keep track of shipments and receipts that flow into the different facilities and to know precisely the contents of each case (Jayaraman, Ross, \& Agarwal, 2008). This control can be completely done using RFID tags while it is not possible with Bar Codes. Indeed the information given to the remote readers gives real time data about the quantity of each batch providing very precise and unique description and position of each product. The managers can follow the products directly and react very quickly in case of problem. Thanks to RFID technology, the inventory control is more consistent owing to "more standardized and efficient sorting processes" (Jayaraman, Ross, \& Agarwal, 2008) and the reuse rate increase significantly with more accurate real time data (Trappey, Trappey, \& Wu, 2010).

As explained previously, the main difference between RFID and other tracking technologies is that RFID provides real time data which should not be useful for MRP at first glance. But if we go deeper in the study, we realize that the planning is more accurate if the data are updated every time. Then the order to the suppliers can be forecasted earlier as explained by Kumar, Dieveney and Dieveney (2009), based on a case study about the RL within the pharmaceutical industry supply chain. They explained the fact that RFID with its real time data reduces the time employed by the manufacturers in forecasting the demand. This IT technology lets the manufacturers and all the entities in the supply chain access the real time information about the quantity, moment, and place (what, when and where) of a specific product is being required. RFID aims to improve batch size, buffers, safety 
factor and more generally reduces uncertainties about quantities in the inventory planning.

\section{Variety}

Wide variety in low quantities is one of the important characteristics of returns (Lee \& Chan, 2008). Therefore one of the uncertainties in RL is variety. Without using RFID technology, identifying the return model (brand) is difficult. In the absence of RFID the identification task have to accomplished by operators which is very slow and sometimes impossible, because for some products the components inside the products may differ which is impossible to be detected without disassembly. So in this case the RFID has advantages over bar codes in a sense that, by using RFID tag, reader and automated machines the sorting of the returned products can be carried completely without any manual labour, which will save a huge amount of cost and time. Now if the sorting is done manually it usually takes place at Centralized Return Center (CRC) and not in Collection Points (Lee \& Chan, 2008) because of the problems in identification. After categorizing different brands they usually sent to their Original Equipment Manufacturer (OEM). This means at least two transportations, one from Collection Points to CRC and then from CRC to OEM. But if the RFID technology is used, the sorting action can be performed in the first step at Collection Points easily and then they can be transported to OEM directly. In this way, both money and time can be saved on transportation.

Quality

The Quality of returned products becomes a very important factor in RL when the purposes of the return are remanufacturing, repair or cannibalization. Because the higher the quality of returns is, the more money OEM can make. Or in other words, the less the components have to be changed, the less money has to be paid for the new components or disassembly.

Besides financial considerations, uncertainty in quality of the returns makes it very difficult to schedule a cannibalization, repair or remanufacturing process because different returns have varying quality levels and consequently each single returned product demands a specific disassembly process. The operator who is responsible for disassembly has to check the quality of each component or sub-assembly. 
Unfortunately normal RFID tags are unable to record any information about the quality of returns. The only opportunity to have a rough estimation on the quality of a return, using normal RFID tags, is when customers register their purchases through internet, therefore in long term remanufacturers could have a rough estimation on the quality levels of returns. However it is interesting to note that this method is practical where the quality of the returns depends on the customers.

Active or semi active tags can be used to save information during the usage of a device. This information can be used during disassembly process. For example Bosch Group is using Electronic Data Log (EDL) in some of their electronic products with electronic motors. Using EDL gave the company the opportunity to know how many hours the electronic device have been worked and they also know the life expectancy of each component of the device. So by knowing these they can have a good estimation on the components that need to be changed (Visich, Li, \& Khumawala, 2007). To make the disassembly process much easier a graphical map of each product and disassembly process can be saved on the tag so that, while disassembly processes it can be shown on a monitor. Those components that should be replaced are in a different color, and then the operator can perform the repair, remanufacturing or cannibalization job faster and with the least mistakes.

\section{Cycle Time}

Cycle time is important from the point that it is possible to predict the amount of returns and some inventory decisions by knowing the average cycle times and variations. Basically there are two types of cycle time-

Product usage time: It is the time elapsed from the moment the customer acquires the product till the moment he returns it to the collection point. By using RFID technology, cycle times are easily detected. Therefore, it is possible to determine the average cycle time and its variation of returns for each product type. This information helps to have a better forecast and consequentially have a more accurate inventory and production planning.

Returns lead time in RLSC: It is the amount of time the returns spent within the RLSC. By using RFID, it is again possible to determine and reduce the cycle time. Because of different quality levels, they need to be processed differently, which leads to different cycle times. As discussed earlier by using RFID time required for 
this processes including sorting and transportation can be done faster. So obviously cycle time would be reduced. Knowing the cycle time and its variation could be used for further planning. Furthermore, when the purpose of return by customer is repair, by knowing the lead time, the customer service center is able to promise a more accurate delivery date.

\section{Market Trend}

Some information from customers can be collected through different ways such as using active RFID tags or EDL which have the capability to save some information during the usage period. Moreover, if the passive tags are used, some information can be saved in the main server when the customer registers those data on internet (Jayaraman, Ross, \& Agarwal, 2008). There are also some more alternatives to collect customer trends through implementing RFID technology.

Market trend uncertainties are a totally different aspect from the set of other uncertainties. Indeed, the market trend information can be used to reduce the rest of uncertainties. The explanation is that by knowing the market behavior, a better prediction can be done about quantity, variety, quality and cycle time of returns. This prediction can be improved by time through measuring and comparing real time data with the prediction values. As an example, by knowing the previous returns records for a specific product it is possible to have a good prediction on the amount of returns for a new developed product from the same family. For certain products (e.g. printer cartridge), one of the concerns of manufacturers is to find ways which encourage customers to return the products. Therefore, by knowing the customers trends they can find solutions to increase returns from costumers (e.g. Discount on next purchases).

\subsection{Conceptual model}

The uncertainties can be categorized in two levels and in five types. The two levels are uncertainty in forecasting the behavior of market and uncertainty in real time information. There are five main different types of uncertainties in $R L$, which are: quality, quantity, variety, returns cycle time and customers or market trends. 


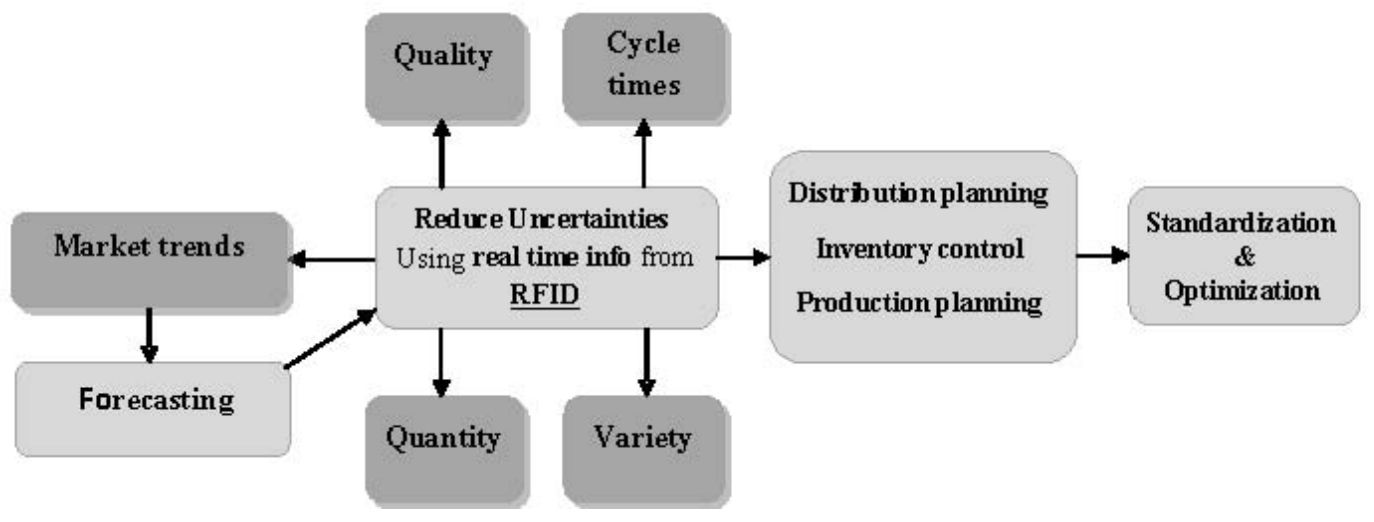

Figure 1. "Conceptual model". Source: own

As it is shown in figure 1 the real time information is the heart of this model. This real time information is collected through implementing RFID technology in RLSC. RFID can directly detect and identify the values of quantity, variety, cycle time and also give estimation on quality conditions of returns.

Besides real time information, other information can be collected from customers' tendencies which can be used to predict future market trends. The accuracy of the predictions can be increased, in long term, by continues comparison between real time data and previous predictions. The data from market trends can be used widely in new products developments as well.

Once uncertainties in RLSC are reduced, a better production planning, inventory control and distribution planning can be done, which prepare the condition to optimize and standardize activities within RLSC.

\subsection{RL Supply Chain and RFID iteration}

In figure 2, the different parts of RLSC (collection points, transportation, sorting etc.) and the impact of RFID tags to reduce uncertainties on these different parts are shown. It is clear that RFID impact on quality, quantity, cycle time and variety can be found during the whole RLSC where impact on market trend is found till collection points only. 


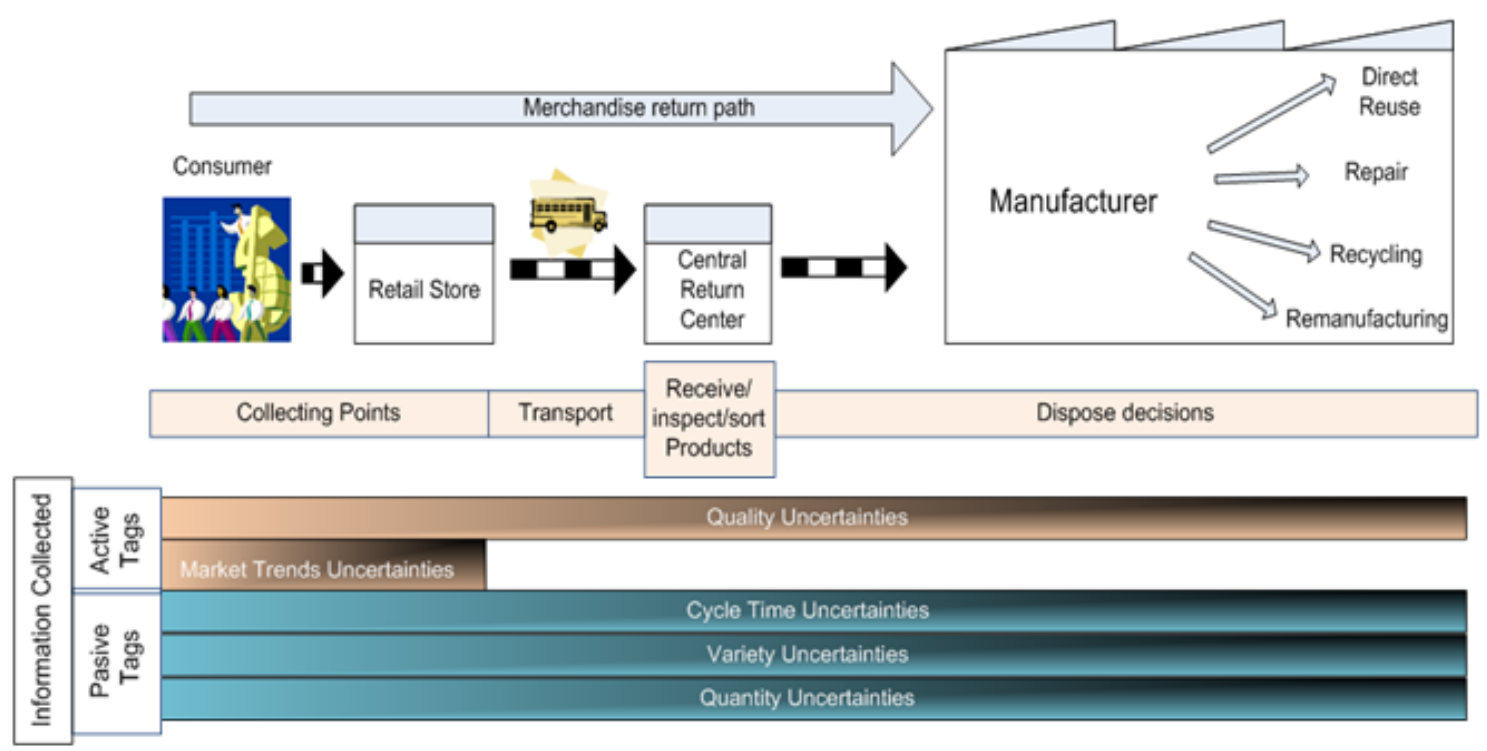

Figure 2. "RL Supply Chain and RFID iteration". Source: own

\section{Obstacles and recommendations}

RFID tool is a very helpful technology in RLSC; however it cannot overcome all the problems. During carrying out this study, three relevant obstacles have show up. They are explained and discuss below with some recommendations and suggestions.

\subsection{Quality and processing sequence}

Although using RFID and EDL technologies in supply chain help the manufacturers to have a better prediction on quality levels of returns and to have a more standardized disassembly process (Visich, Li, \& Khumawala, 2007), it is still not that easy to determine the quality of the inner components of the returns before disassembling them. Besides, even if the quality of components is verified before disassembly, the disassembly sequence is still not the same for all the products because the sequence depends on the quality of components (the one which required to be replaced, etc.) (Fleischmann \& Bloemhof-Ruwaard, 1997). Imagine a production floor that any incoming product need a different production sequence; standardization for such a process would be difficult because the production system would be somewhere between project and job shop systems. 
This standardization is important from two aspects. First, if companies use the same standards in their designs for assembly of their products, the manufacturers could disassemble returned products originally made in other companies with a higher efficiency. Secondly, the disassembly process should be taken into consideration from the early stages of the product developments. A new approach has been developed, called Design for Disassembly, which could meet this prob. This can also lead to an easier disassembly and increase the capability of manufacturers for processing the returns. By accomplishing these two aspects, disassembly process can be done more effectively in just one station, so different processes in different stations are not needed.

\subsection{Collecting points and different standards}

If the collecting points try to collect different products from different manufacturers and record their information through using RFID, they face a major problem, which is the difference between the standards from the manufacturers. Therefore some tags cannot be detected by remote readers. Some argue that the reason why manufacturers do not use the same standard is that they do not want to reveal their information to others.

To overcome these problems, RFID users should use a blend of standard and customize readers. On the one hand, the advantage is that some part of the information which is useful for $\mathrm{RL}$ activities can be read by any reader which eases the RL activities. But on the other hand some confidential information will be read by all manufacturers and the owner of the returned product.

\subsection{RFID and global market}

Even if it has some unique advantages, the mainstream application of RFID is not seen globally. There are some certain challenges which organization faces in deploying this technology. RFID is not a simple plug-and-play technology. A supplier cannot simply slap a smart label with an RFID tag embedded in it because retailers need sensible solutions for hundreds of products. Moreover, suppliers need different compliance requirements for different retailers (RFID Solution in Reverse Logistics, A case study in Scintel). This is an obstacle for RFID implementation and the solutions might include the use of a specific type of tag 
with a precise location on the product and an arrangement for the cases in a special configuration on a pallet.

In their literature survey Sarac, Nabil and Dauzère-Péres (2010) provide useful information about the limited application of RFID technologies. Lack of international standard has been identified as one of the major disadvantages. Significant differences have been found between the UHF (Ultra High Frequency) in Europe and USA. Besides they have found that metal and liquid environment can disturb reading performances of RFID technologies. Standardization of RFID technologies; and numerous tests to obtain an optimum technology according to the environment are suggested for possible solutions.

According to Want (2006), there are three main issues why RFID is not widely adopted. First issue is cost: as RFID is not so much cheap with the aspects of traditional technologies, it cannot compete with others. RFID tags are available at low prices but it is still much more expensive than printed labels. Secondly, design is another issue where engineering is required in tags and readers. A guarantee about the identification is needed. By improving the tag antenna design, some of these issues can be solved. "Reader collision problem" must be avoided which will interfere with each other. Final issue is acceptance: laws and legislation against the potential of RFID misuse might be introduced to provide assurance to the users. Despite these challenges, RFID continues to make inroads into inventory control systems, and it is only a matter of time before the component costs fall low enough to make RFID an attractive economic proposition.

\section{Conclusions and perspectives}

To make RL more attractive from the economic point of view, the right planning and control is essential. Without very accurate information, planning and controlling cannot be as efficient as in FL. Using RFID technology, manufacturers can obtain some useful information that is crucial for standardizing and planning CLSC. It can be explained more tangibly if we look at the MPS table, a planning tool. For example it shows that lead time, forecasting volume, demand and available to promise are the information needed to do the MPS. This information can be collected through implementing RFID in the supply chain. The collected information assists the RLSC to reduce the uncertainties. These uncertainties have 
been sorted into five main groups: Quantity, Variety, Cycle time, Quality and Market trend. Once these uncertainties reduced, a more accurate planning for production, inventory and distribution take place which enables manufacturers to standardize their activities and optimize them.

\section{References}

Chouinard, M., D'Amours, S., \& Aït-Kadi, D. (2005). Integration of reverse logistics activities within a supply chain information system. Computers in Industry, 56(1), 105- 124.

\section{doi: 10.1016/j.compind.2004.07.005}

Fleischmann, M., \& Bloemhof-Ruwaard, J. M. (1997). Quantitative Models for Reverse Logistics: A review. European journal of Operations Research, 103(1), 117.

doi: $10.1016 / 50377-2217(97) 00230-0$

Guide, V. jr., Harrison, T., \& Van Wassenhove, L. (2003). The Challenge of ClosedLoop Supply Chains. Interfaces, 33(6), 3-6.

doi: 10.1287/inte. 33.6.1.25185

Jayaraman, V., Ross, A. D., \& Agarwal, A. (2008). Role of information technology and collaboration in reverse logistics supply chains. International Journal of Logistics: Research and Applications, 11(6), 409-425.

doi: $10.1080 / 13675560701694499$

Kärkkäinen, M. (2003). Increasing efficiency in the supply chain for short shelf life goods using RFID tagging. International Journal of Retail \& Distribution Management, 31(10), 529-536.

doi: $10.1108 / 09590550310497058$

Kumar, S., Dieveney, E., \& Dieveney, A. (2009). Reverse logistics process control measures for the pharmaceutical industry supply chain. International Journal of Productivity and Performance Management, 58(2), 188-204.

doi: 10.1108/17410400910928761 
Langer, N., Forman, C., Kekre, S., \& Scheller-Wolf, A. (2007). Assessing the impact of RFID on return center logistics. Interfaces, 37(6), 501-514.

doi: $10.1287 /$ inte. 1070.0308

Lee, C. K. M., \& Chan, T. M. (2008). Development of RFID-based Reverse Logistic System. Expert Systems with Applications, 36(5), 9299-9307. doi: 10.1016/j.eswa.2008.12.002

Poole, K. (2003). Seizing the potential of the service supply chain. Supply Chain Management Review, 7(4), 54-61.

Sarac, A., Nabil, A., \& Dauzère-Péres, S. (2010). A literature review on the impact of RFID technologies on supply chain management. International J ournal of Production Economics, 128(1), 77-95.

doi: 10.1016/j.ijpe.2010.07.039

Thierry, M. C., Salomon, M., Van Nunen, J., \& Van Wassenhove, L. (1995). Strategic Issues in Product Recovery Management. California Management Review, 37(2), 114-135.

Thoroe, L., Melski, A., \& Schumann, M. (2009). The impact of RFID on management of returnable containers. Berlin / Heidelberg: Springer, 90(2), 115-124.

Trappey, A. J. C., Trappey, C. V., \& Wu, C-R. (2010). Genetic algorithm dynamic performance evaluation for RFID reverse logistic management. Expert Systems with Applications, 37(8), 7329-7335.

doi: 10.1016/j.eswa.2010.04.026

Üstündag, A., Baysan, S., \& Çevikcan, E. (2007). A Conceptual Framework for Economic Analysis of RFID Reverse Logistics via Simulation. RFID Eurasia, 2007 1st Annual, 5-6 Sept., 1-5.

Visich, J. K., Li, S., \& Khumawala, B. M. (2007). Enhancing Product Recovery Value in Closed-loop Supply Chains with RFID. Journal of Managerial Issues, 19(3), 436452.

Want, R. (2006). An Introduction to RFID Technology. IEEE, 5(1), 25-33. 
Article's contents are provided on a Attribution-Non Commercial 3.0 Creative commons license. Readers are allowed to copy, distribute and communicate article's contents, provided the author's and Journal of Industrial Engineering and Management's names are included. It must not be used for commercial purposes. To see the complete license contents, please visit http://creativecommons.org/licenses/by-nc/3.0/. 